\title{
Investigation on Power Dissipation in the Saturated Iron-core Superconducting Fault Current Limiter
}

\author{
Boyang Shen, Chao Li, Jianzhao Geng, Qihuan Dong, Jun Ma, James Gawith, Kaihe Zhang, Jiabin Yang, Xinru Li, \\ Zhen Huang, and T. A. Coombs
}

\begin{abstract}
This article presents the power dissipation analysis on saturated iron-core superconducting fault current limiter (SISFCL). The modeling of SISFCL together with its power dissipation computation on high-temperature superconducting (HTS) coil were executed by the $\boldsymbol{H}$-formulation model implemented into the finite-element method (FEM) software package COMSOL. The model was based on the practical threephase $35 \mathrm{kV} / 90 \mathrm{MVA}$ SISFCL. The AC magnetic field in the crucial parts of SISFCL was studied to discover the origin of power loss on HTS coil. The instantaneous power dissipations in the HTS coil with increasing DC bias current were computed and compared. Analysis proved that power dissipation in the HTS coil of SISFCL should be taken into account for the real operation.
\end{abstract}

Index Terms - Saturated iron-core superconducting fault current limiter (SISFCL), High-temperature superconducting (HTS) coil, Power dissipation, AC loss, Finite element analysis.

\section{INTRODUCTION}

$\mathrm{T}$ he generation, distribution and consumption of the future energy will be greatly changed by the development of the smart grid [1]. With an increasing number of power generations and high penetration of distributed generation, the power system is suffering high level of fault current, which is a huge challenge for the secure and reliability of the power system. The superconducting fault current limiter is a good solution to the problems in electrical power systems [2], and even in transportation systems [3-7]. It can present large impedance to limiter the fault current during the fault and shows zero-resistance in the normal operation of the power system. Early works on superconducting fault current limiters have been demonstrated in [8-10]. Considering the advantages of requiring no quench of superconducting coils, the application of the saturated iron-core superconducting fault current limiter (SISFCL) in the extra high voltage transmission line seems more promising [11-14].

Previous works on design, simulation and experiment of saturated iron-core superconducting fault current limiter have been reported in [11-20]. In these studies, the power dissipation in the DC superconducting coil was neglected because superconductivity is generally regarded as zero resistivity in DC condition. However, one issue was still missing in the

This work was supported by the China Scholarship Council (CSC) and the Cambridge Trust. (Corresponding author: Chao Li.)

B. Shen, C. Li, J. Geng, Q. Dong, J. Ma, J. Gawith, J. Yang, X. Li, and T. A. Coombs are with the Electrical Engineering Division, Department of Engineering, University of Cambridge, Cambridge CB3 OFA, U.K. (e-mail: cl644@cam.ac.uk)

K. Zhang is with the College of Electrical Engineering, Zhejiang University, Hangzhou 310007, China. (e-mail: 3100100854@zju.edu.cn)

Z. Huang is with the School of Electronic Information and Electrical Engineering, Shanghai Jiao Tong University, Shanghai 200240, China. (e-mail: zhen.huang@sjtu.edu.cn) previous studies: there are alternating magnetic fields leaking from the iron-cores, and these leaking AC field can cause power dissipation in superconducting coil even it is operating in DC condition [21]. Therefore, it is necessary to investigate the power loss in the SISFCL as it potentially affects the overall efficiency and economic performance of SISFCL.

We used the practical three-phase $35 \mathrm{kV} / 90$ MVA SISFCL as the analysis model, whose configuration is shown in Fig. 1(a). The three-phase 3D model was simplified to 2D cross-section model. It is understandable that the power dissipation in the real 3D superconducting coil is different in each radial cross-section, and the dissipation is also smaller than the specific 2D cross-section model (the cross-section of

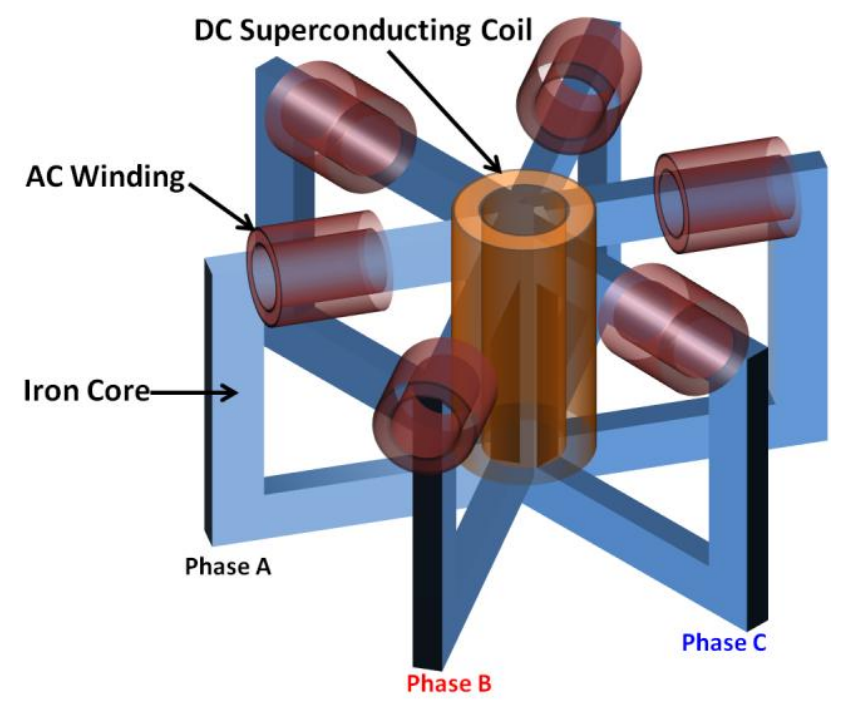

(a)

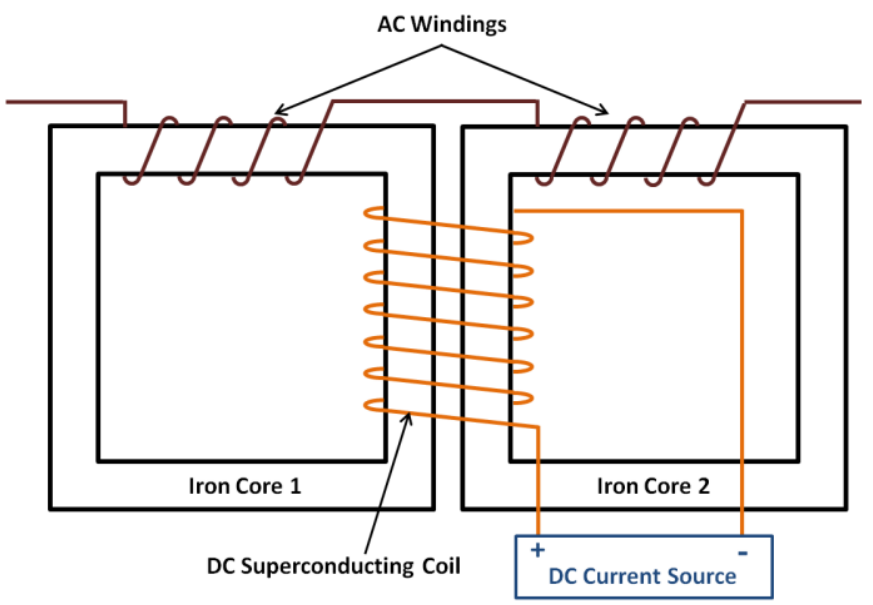

(b)

Fig. 1. (a) Configuration of three-phase saturated iron-core superconducting fault current limiter, (b) Circuit schematic (single-phase) of saturated ironcore superconducting fault current limiter. 


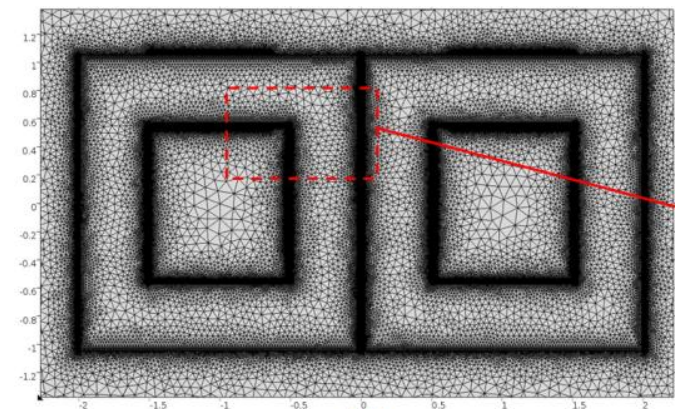

(a)

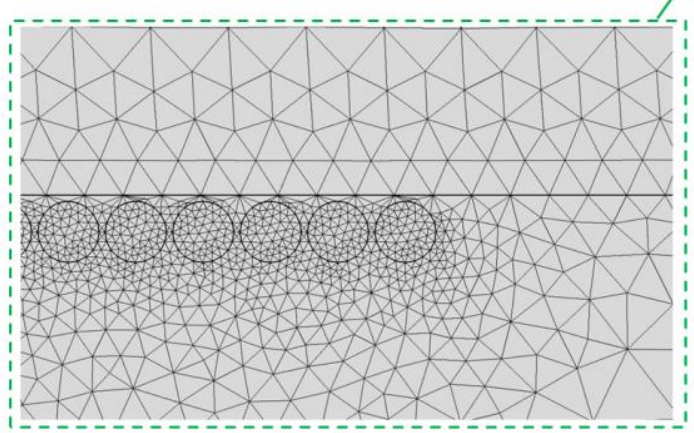

(c)

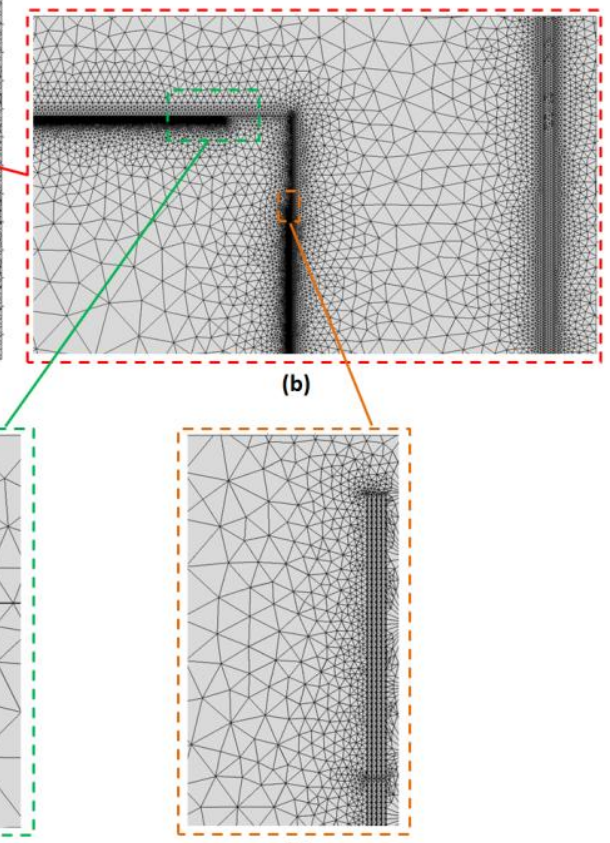

(d)

Fig. 2. (a) Mesh of SISFCL, (b) Zoomed-in part (red dash area) of (a), (c) Zoomed-in part (green dash area) of (b) to show the details of AC windings, (d) Zoomed-in part (orange dash area) of (b) to show the details of HTS tapes.

TABLE 1. PARAMETERS FOR THE SISFCL MODEL

\begin{tabular}{ll}
\hline \hline Parameters & Value \\
\hline Superconducting layer thickness & $1 \mu \mathrm{m}$ \\
HTS Tape width & $12 \mathrm{~mm}$ \\
Superconducting layer separation & $0.2 \mathrm{~mm}$ \\
DC HTS coil diameter & $1024 \mathrm{~mm}$ \\
Turns of HTS tapes & $300(60 \times 5)$ \\
Copper cable diameter & $10 \mathrm{~mm}$ \\
AC copper winding diameter & $512 \mathrm{~mm}$ \\
Rated AC current & $1.5 \mathrm{kA}$ \\
Turns of copper cable & 78 \\
Iron-core width (inner window) & $1000 \mathrm{~mm}$ \\
Iron-core height (inner window) & $1100 \mathrm{~mm}$ \\
Iron-core width (outer window) & $2000 \mathrm{~mm}$ \\
Iron-core height (outer window) & $2100 \mathrm{~mm}$ \\
$\mu_{0}$ & $4 \pi \times 10^{-7} \mathrm{H} / \mathrm{m}$ \\
$n$ (power factor for E-J power law) & 25 \\
$J_{c 0}$ & $4.75 \times 10^{10} \mathrm{~A} / \mathrm{m}^{2}$ \\
$E_{0}$ & $10^{-4} \mathrm{~V} / \mathrm{m}$ \\
$B_{C}$ & $35 \mathrm{mT}$ \\
$b$ & 0.6 \\
$k$ & 0.25 \\
\hline \hline
\end{tabular}

schematic (single-phase) shown in Fig. 1(b)). However, the 2D cross-section model in this paper demonstrates the worst case which could provide the reasonable upper limit of the power dissipation in such a SISFCL. This article exhibits the AC power dissipation analysis consisting of the magnetic field study, instantaneous loss and systematic loss calculation of the SISFCL.

\section{MODELING}

\section{A. H-formulation}

For the purpose of computing the power dissipation in SISFCL, the $\boldsymbol{H}$-formulation determined by Maxwell's equations has been selected as the proper method. $\boldsymbol{H}$-formulation consists of (1) Maxwell Ampere's Law, (2) Faraday's Law, (3) Constitutive Law, (4) Ohm's Law and (5) $E-J$ power Law $[22,23]$ :

$$
\begin{gathered}
\nabla \times \boldsymbol{H}=\boldsymbol{J} \\
\nabla \times \boldsymbol{E}=-\frac{\partial \boldsymbol{B}}{\partial t} \\
\boldsymbol{B}=\mu_{0} \mu_{r} \boldsymbol{H} \\
\boldsymbol{E}=\rho \boldsymbol{J} \\
E=E_{0}\left(\frac{J}{J_{c}}\right)^{n}
\end{gathered}
$$

Where the magnetic field intensity is $\boldsymbol{H}$, the current density is $\boldsymbol{J}$, the electric field is $\boldsymbol{E}$, the resistivity is $\rho$, the magnetic flux density is $\boldsymbol{B}$, the permeability of free space is $\mu_{0}$, the relative permeability is $\mu_{r}$. Equation (5) exhibits the $E$ - $J$ power law of HTS modeling, where the characteristic electric field is $E_{0}$, the critical current density is $J_{c}$, and the power factor is $n$. If we combine equation (1), (2), (3), (4) and (5), the general form of partial differential equation (PDE), for the variables $\boldsymbol{H}$ is [24, 25]:

$$
\frac{\partial\left(\mu_{0} \mu_{r} \boldsymbol{H}\right)}{\partial t}+\nabla \times(\rho \nabla \times \boldsymbol{H})=0
$$

Equation (6) can be solved by the FEM software COMSOL [26, 27].

\section{B. Modeling and power dissipation calculation of SISFCL}

The $35 \mathrm{kV} / 90$ MVA SISFCL cross-section model is composed of 3 main parts: AC current winding (copper cable), DC superconducting coil, and iron-core [28]. In this study, we used a typical $35 \mathrm{kV} / 90$ MVA SISFCL configuration using $1.5 \mathrm{kA}$ rated AC current, and 78 turns AC windings. The geometry of the SISFCL model was approximately based on [18]. To achieve the high accuracy calculation of power loss in the superconducting coil in SISFCL, we utilized the real dimension of typical HTS tapes: the superconducting layer 1 $\mu \mathrm{m}$ thick. The electromagnetic characteristic of iron-core 


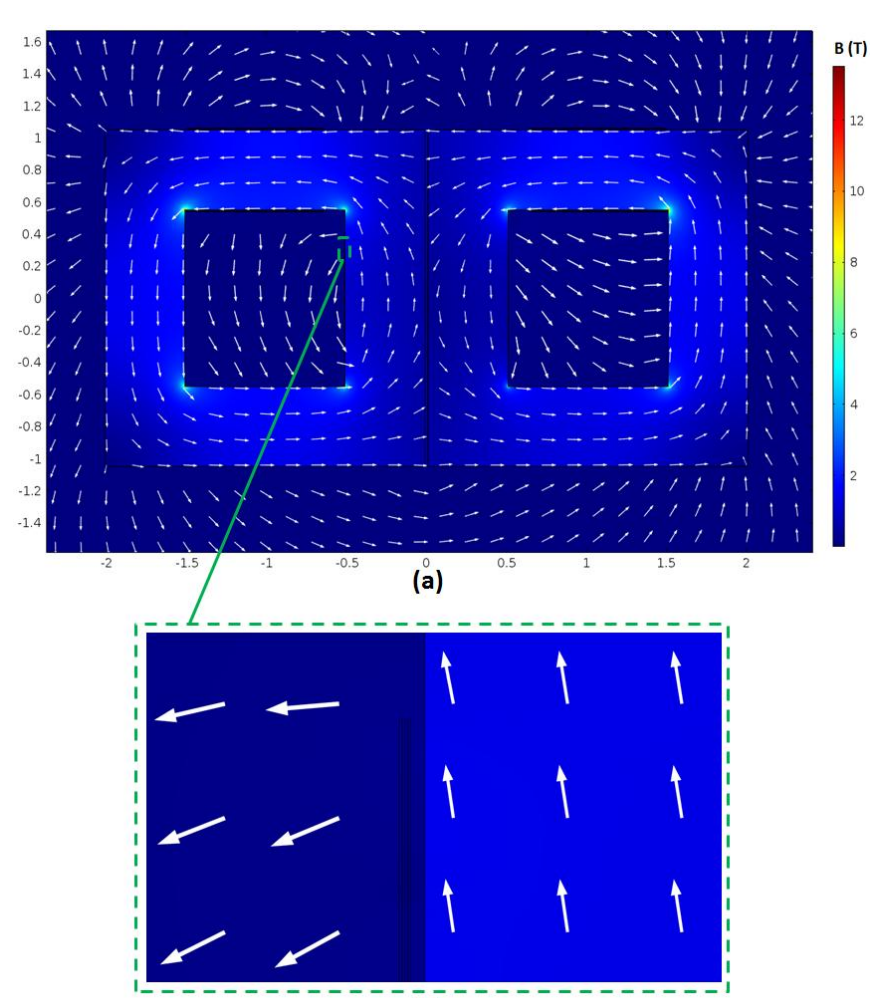

(b)

Fig. 3. (a) Overall magnetic field around the SISFCL during general operation (AC winding $1.5 \mathrm{kA}$, peak point; DC bias current $200 \mathrm{~A}$ ), (b) Zoomed-in part (green dash area) of (a) to show more details of the transition between HTS tapes and iron-core, with some AC magnetic field leaking out from the iron-core.

material was imported to this SISFCL model using the method [29]. The detailed design parameters of SISFCL model are listed in TABLE I. The mesh of SISFCL is shown in Fig. 2. Fig. 2(b) is the zoomed-in part (red dash area) of Fig. 2(a). To be more precise, Fig. 2(c) is the zoomed-in part (green dash area) of Fig. 2(b) to demonstrate the details of AC windings, and Fig. 2 (d) zoomed-in part (orange dash area) of Fig. 2(b) to show the details of HTS tapes. The power factor for the $E-J$ power law was used the typical value 25. An anisotropic B-dependent critical current model (with magnetic field in perpendicular and parallel directions) [30] was implemented into the modeling:

$$
J_{c}(B)=\frac{J_{c 0}}{\left(1+\frac{\sqrt{\left(k \boldsymbol{B}_{\text {para }}\right)^{2}+\boldsymbol{B}_{\text {perp }}^{2}}}{\boldsymbol{B}_{c}}\right)^{b}}
$$

where $J_{c 0}=4.75 \times 10^{10} \mathrm{~A} / \mathrm{m}^{2}, B_{c}=0.035, b=0.6$, and $k=0.25$. A static model determined by equation (7) estimated the critical current $I_{c}$ of a single tape is 470 A [30].

The power frequency, $50 \mathrm{~Hz}$, was used for the whole modeling, thus it was justifiable to neglect the eddy current AC losses in the copper and other metal layers of HTS tape [31]. Consequently, only the hysteresis (magnetization) losses in the superconducting layer make contribution to the power dissipation. Transport currents were imposed into crosssections using the "Global Constraint" function in COMSOL. $\Omega$ is the domain of interest, and $\mathrm{T}$ is the period of cycle. The

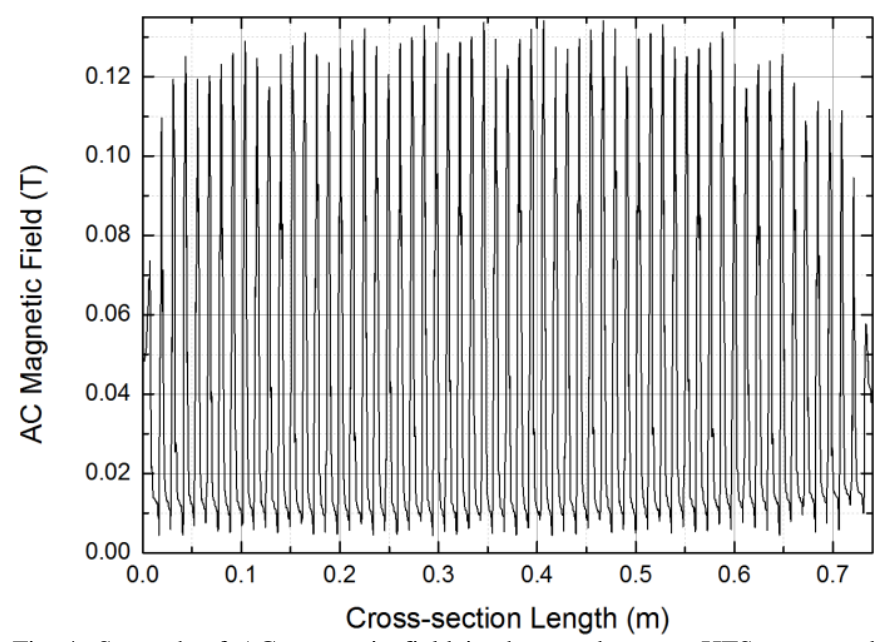

Fig. 4. Strength of AC magnetic field in the gap between HTS tapes and iron-core, with DC current in HTS coil $0 \mathrm{~A}$, and AC current in the winding $1.5 \mathrm{kA}$.

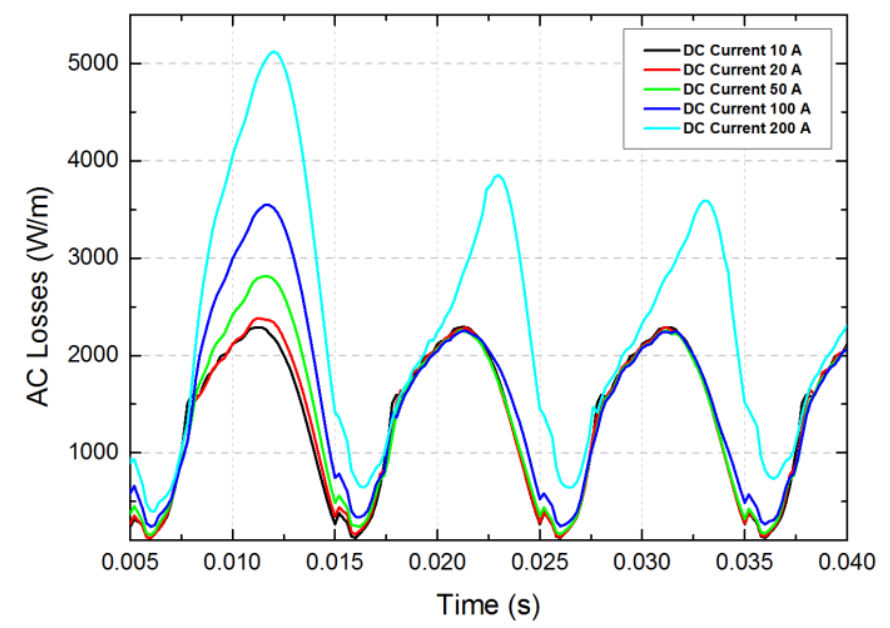

Fig. 5. Instantaneous AC losses per cross-section (Watts/meter) in the HTS coil, with DC bias current increasing from 10 A to $200 \mathrm{~A}$.

power dissipation was computed by the integration of $\boldsymbol{E}$ and $\boldsymbol{J}$ on the superconducting domain [24, 32]:

$$
Q=\frac{2}{T} \int_{0.5 T}^{T} \int_{\Omega} \boldsymbol{E} \cdot \boldsymbol{J} d \Omega d t
$$

\section{ANALYSIS AND DISCUSSION}

Fig. 3(a) presents the overall magnetic field around the SISFCL during general operation (AC winding $1.5 \mathrm{kA}$, peak point; DC bias current $200 \mathrm{~A}$ ). The white arrows reveal the direction of AC magnetic field. It can be discovered the strong magnetic field flows within the iron-cores, but relative low magnetic field distributes outside the iron-cores, which could be due to the much higher permeability of iron-core material. Fig. 3(b) is the zoomed-in part (green dash area) of Fig. 3(a) to show more details of the transition between HTS tapes and iron-core, and it can be seen some AC magnetic field leaking out from the iron-core. Fig. 3(b) reveals direction of the leaking AC magnetic field had relatively big perpendicular component to the HTS tape surface, which could be the main origin of power dissipation in the HTS coil.

To dedicate more details, Fig. 4 illustrates the strength of AC magnetic field in the gap between HTS tapes and iron-core. The DC current in HTS coil was set to be $0 \mathrm{~A}$, and AC current 


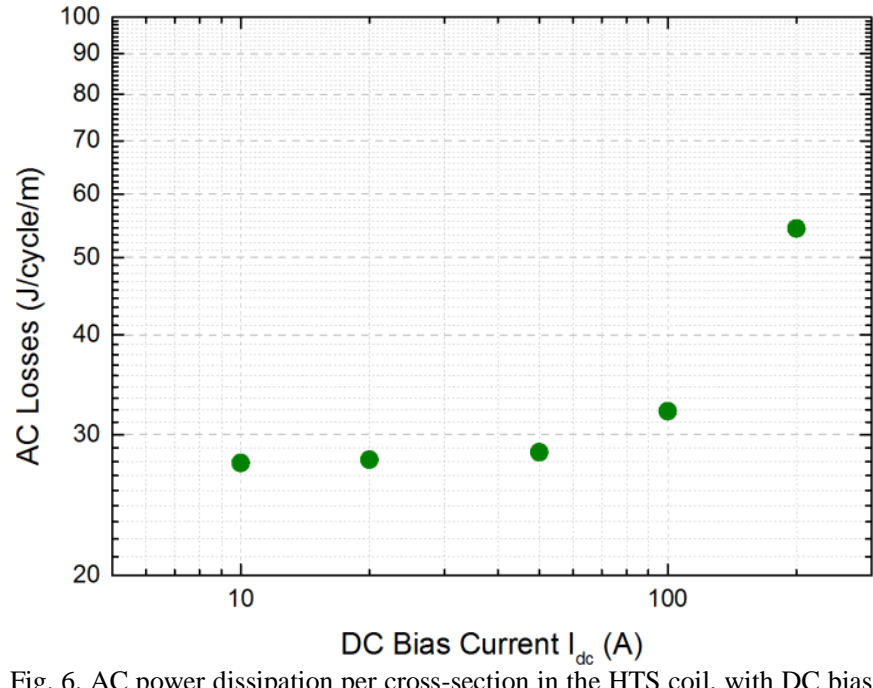

Fig. 6. AC power dissipation per cross-section in the HTS coil, with DC bias current increasing from $10 \mathrm{~A}$ to $200 \mathrm{~A}$.

in the winding was set to be $1.5 \mathrm{kA}$. It can be seen that the leaking AC magnetic field along the gap varying from $10 \mathrm{mT}$ to $130 \mathrm{mT}$, with the average value around $70 \mathrm{mT}$.

Fig. 5 presents the instantaneous AC losses per crosssection (Watts/meter) in the HTS coil, with DC bias current increasing from 10 to $200 \mathrm{~A}$. It can be seen that frequency of instantaneous loss was two times of the frequency of $\mathrm{AC}$ winding current. The first high peaks of instantaneous AC loss were due to the superposition of the charging process of DC HTS coil in simulation. Once getting into steady-state, for the case: DC bias current $200 \mathrm{~A}$, the average instantaneous AC loss per cross-section was approximate $2102 \mathrm{~W} / \mathrm{m}$.

Fig. 6 presents the AC power dissipation per cross-section in the HTS coil with DC bias current increasing from $10 \mathrm{~A}$ to $200 \mathrm{~A}$, in terms of the typical loss unit Joule/cycle/meter. The increasing rate of loss was not linear. It can be observed that the difference of loss between DC bias current of $100 \mathrm{~A}$ and $200 \mathrm{~A}$, was greater than that between DC bias current of $10 \mathrm{~A}$ and $100 \mathrm{~A}$. There were two possible reasons why the loss massively increased with higher DC bias current: (i) higher DC bias current generated more self-field which could further decrease critical current of the HTS coil; (ii) dynamic resistance loss increased more with higher DC bias current. Similar phenomenon can be found in [33].

To summarize, the power dissipation in the DC HTS coil of SISFCL should be taken into account. For example, with the case $1.5 \mathrm{kA}$ AC winding, and $200 \mathrm{~A}$ DC bias HTS coil, the average loss per cross-section in the HTS coil was around $2102 \mathrm{~W} / \mathrm{m}$. If multiplying by the perimeter of HTS coil $3.22 \mathrm{~m}$, the total calculated loss of the HTS coil in SISFCL was approximately $6762 \mathrm{~W}$. Although in the introduction part we have mentioned this 2D cross-section study shows the worst case which could provide the upper loss limit, the real total loss should still be in the kilo Watts level. If DC bias current increasing to high value, the loss will further increase. This power dissipation will convert to the form of heat, which will also cause burden for the cryogenic system of SISFCL.

\section{CONCLUSION}

The modeling and power dissipation calculation of SISFCL were carried out using $\boldsymbol{H}$-formulation model by the FEM package COMSOL. The model was on the basis of the practical three-phase $35 \mathrm{kV} / 90$ MVA SISFCL. The AC magnetic field between HTS coil and iron-core was analyzed to find the cause of AC power dissipation in HTS coil. The power dissipations per cross-section in the HTS coil with increasing DC bias current were computed and compared. The results show that the total AC power loss in the HTS coil of SISFCL should be in the kilo Watts level, and will even further increase with higher DC bias current. To conclude, for the real operation, the power dissipation in the HTS coil of SISFCL should be taken into consideration.

\section{ACKNOWLEDGMENTS}

Some authors are research students, and they want to express appreciation to the China Scholarship Council (CSC) and the Cambridge Trust, for their scholarships and significant supports. This study was carried out at the Electrical Engineering Division, Department of Engineering, University of Cambridge. Authors are very grateful to members of staff for their important assistance.

\section{REFERENCES}

[1] M. Liserre, T. Sauter, and J. Y. Hung, "Future energy systems: Integrating renewable energy sources into the smart power grid through industrial electronics," IEEE industrial electronics magazine, vol. 4, no. 1, pp. 18-37, 2010.

[2] B. Raju, K. Parton, and T. Bartram, "A current limiting device using superconducting dc bias applications and prospects," IEEE Transactions on Power Apparatus and Systems, no. 9, pp. 3173-3177, 1982.

[3] Y. Chen, X. Liu, J. Sheng, L. Cai, Z. Jin, J. Gu, Z. An, X. Yang, and Z. Hong, "Design and application of a superconducting fault current limiter in DC systems," IEEE Trans. Appl. Supercond., vol. 24, no. 3, pp. 1-5, 2014.

[4] P. J. Masson, and C. A. Luongo, "High power density superconducting motor for all-electric aircraft propulsion," IEEE Trans. Appl. Supercond., vol. 15, no. 2, pp. 2226-2229, 2005.

[5] C. A. Luongo, P. J. Masson, T. Nam, D. Mavris, H. D. Kim, G. V. Brown, M. Waters, and D. Hall, "Next generation more-electric aircraft: a potential application for HTS superconductors," IEEE Trans. Appl. Supercond., vol. 19, no. 3, pp. 1055-1068, 2009.

[6] Z. Deng, W. Zhang, J. Zheng, B. Wang, Y. Ren, X. Zheng, and J. Zhang, "A high-temperature superconducting Maglev-evacuated tube transport (HTS Maglev-ETT) test system,” IEEE Trans. Appl. Supercond., vol. 27, no. 6 , pp. 1-8, 2017.

[7] Z. Deng, W. Zhang, J. Zheng, Y. Ren, D. Jiang, X. Zheng, J. Zhang, P. Gao, Q. Lin, and B. Song, "A high-temperature superconducting maglev ring test line developed in Chengdu, China," IEEE Trans. Appl. Supercond., vol. 26, no. 6, pp. 1-8, 2016.

[8] J. Jin, C. Grantham, H. Lui, and S. Dou, "Prototype Fault Current Limiter with a High Tc Superconducting Coil," Journal of Electrical and Electronics Engineering, Australia, vol. 15, pp. 117-117, 1995.

[9] J. Jin, S. Dou, H. Liu, and C. Grantham, "Preparation of high Tc superconducting coils for consideration of their use in a prototype fault current limiter," IEEE Trans. Appl. Supercond., vol. 5, no. 2, pp. 10511054, 1995.

[10] J. Jin, S. Dou, H. Liu, C. Grantham, Z. Zeng, Z. Liu, T. Blackburn, X. Li, H. Liu, and J. Liu, "Electrical application of high Tc superconducting saturable magnetic core fault current limiter," IEEE Trans. Appl. Supercond., vol. 7, no. 2, pp. 1009-1012, 1997.

[11] Y. Xin, W. Gong, X. Niu, Z. Cao, J. Zhang, B. Tian, H. Xi, Y. Wang, H. Hong, and Y. Zhang, "Development of saturated iron core HTS fault current limiters," IEEE Trans. Appl. Supercond., vol. 17, no. 2, pp. 1760$1763,2007$.

[12] J. Yuan, H. Zhou, P. Gan, Y. Zhong, Y. Gao, K. Muramatsu, Z. Du, and B. Chen, "A novel concept of fault current limiter based on saturable core in high voltage DC transmission system," AIP Advances, vol. 8, no. 5, pp. 056636, 2018.

[13] B. Li, C. Li, F. Guo, Y. Xin, C. Wang, and X. Pang, "Coordination of superconductive fault current limiters with zero-sequence current 
protection of transmission lines," IEEE Trans. Appl. Supercond., vol. 24, no. 5, pp. 1-5, 2014.

[14] C. Li, B. Li, F. Guo, J. Geng, X. Zhang, and T. Coombs, "Studies on the active SISFCL and its impact on the distance protection of the EHV transmission line," Protection and Control of Modern Power Systems, vol. 1, no. 1, pp. $18,2016$.

[15] B. Li, C. Li, F. Guo, and Y. Xin, "Overcurrent protection coordination in a power distribution network with the active superconductive fault current limiter," IEEE Trans. Appl. Supercond., vol. 24, no. 5, pp. 1-4, 2014.

[16] B. Li, C. Li, and F. Guo, "Application studies on the active SISFCL in electric transmission system and its impact on line distance protection," IEEE Trans. Appl. Supercond., vol. 25, no. 2, pp. 1-9, 2015.

[17] Y. Xin, W. Gong, X. Niu, Y. Gao, Q. Guo, L. Xiao, Z. Cao, H. Hong, A. $\mathrm{Wu}$, and $\mathrm{Z}$. Li, "Manufacturing and test of a $35 \mathrm{kV} / 90$ MVA saturated iron-core type superconductive fault current limiter for live-grid operation," IEEE Trans. Appl. Supercond., vol. 19, no. 3, pp. 1934-1937, 2009.

[18] W. Gong, J. Zhang, Z. Cao, H. Hong, B. Tian, Y. Wang, J. Wang, X. Niu, J. Qiu, S. Wang, and Y. Xin, "HTS dc bias coil for $35 \mathrm{kV} / 90$ MVA saturated iron-core fault current limiter," Phys. C, Supercond., vol. 468, no. $15-20$, pp. 2050-2053, 2008.

[19] B. Li, F. Jing, J. Jia, and B. Li, "Research on saturated iron-core superconductive fault current limiters applied in VSC-HVDC systems," IEEE Trans. Appl. Supercond., vol. 26, no. 7, pp. 1-5, 2016.

[20] B. Li, F. Guo, J. Wang, and C. Li, "Electromagnetic transient analysis of the saturated iron-core superconductor fault current limiter," IEEE Trans. Appl. Supercond., vol. 25, no. 3, pp. 1-5, 2015.

[21] C. Li, J. Geng, J. Gawith, B. Shen, X. Zhang, H. Zhang, J. Ma, and T. A. Coombs, "Design for a Persistent Current Switch Controlled by Alternating Current Magnetic Field," IEEE Trans. Appl. Supercond., vol. 28, no. 4, pp. 1-5, 2018.

[22] Z. Hong, A. M. Campbell, and T. A. Coombs, "Numerical solution of critical state in superconductivity by finite element software," Supercond. Sci. Technol., vol. 19, no. 12, pp. 1246, 2006.

[23] J. Zheng, H. Huang, S. Zhang, and Z. Deng, "A General Method to Simulate the Electromagnetic Characteristics of HTS Maglev Systems by Finite Element Software," IEEE Trans. Appl. Supercond., vol. 28, no. $5,2018$.

[24] B. Shen, J. Li, J. Geng, L. Fu, X. Zhang, H. Zhang, C. Li, F. Grilli, and T. A. Coombs, "Investigation of AC losses in horizontally parallel HTS tapes," Supercond. Sci. Technol., vol. 30, no. 7, 2017.

[25] B. Shen, L. Fu, J. Geng, X. Zhang, H. Zhang, Q. Dong, C. Li, J. Li, and T. A. Coombs, "Design and simulation of superconducting Lorentz Force Electrical Impedance Tomography (LFEIT)," Phys. C, Supercond., vol. 524, pp. 5-12, 2016.

[26] B. Shen, L. Fu, J. Geng, H. Zhang, X. Zhang, Z. Zhong, Z. Huang, and T. A. Coombs, "Design of a Superconducting Magnet for Lorentz Force Electrical Impedance Tomography," IEEE Trans. Appl. Supercond., vol. 26, no. 3, 2016.

[27] B. Shen, J. Geng, C. Li, X. Zhang, L. Fu, H. Zhang, J. Ma, and T. Coombs, "Optimization study on the magnetic field of superconducting Halbach Array magnet," Phys. C, Supercond., vol. 538, pp. 46-51, 2017.

[28] Y. Xin, H. Hong, J. Wang, W. Gong, J. Zhang, A. Ren, M. Zi, Z. Xiong, D. Si, and F. Ye, "Performance of the $35 \mathrm{kV} / 90$ MVA SFCL in live-grid fault current limiting tests," IEEE Trans. Appl. Supercond., vol. 21, no. 3, pp. 1294-1297, 2011.

[29] M. Zhang, J. Kvitkovic, S. Pamidi, and T. Coombs, "Experimental and numerical study of a YBCO pancake coil with a magnetic substrate," Supercond. Sci. Technol., vol. 25, no. 12, pp. 125020, 2012.

[30] F. Grilli, F. Sirois, V. M. Zermeno, and M. Vojenčiak, "Self-consistent modeling of the Ic of HTS devices: How accurate do models really need to be?," IEEE Trans. Appl. Supercond., vol. 24, no. 6, pp. 1-8, 2014.

[31] B. Shen, J. Li, J. Geng, L. Fu, X. Zhang, C. Li, H. Zhang, Q. Dong, J. $\mathrm{Ma}$, and T. A. Coombs, "Investigation and comparison of AC losses on stabilizer-free and copper stabilizer HTS tapes," Phys. C, Supercond., vol. 541, pp. 40-44, 2017.

[32] B. Shen, J. Geng, X. Zhang, L. Fu, C. Li, H. Zhang, Q. Dong, J. Ma, J. Gawith, and T. A. Coombs, "AC losses in horizontally parallel HTS tapes for possible wireless power transfer applications," Phys. C, Supercond., vol. 543, pp. 35-40, 2017.

[33] B. Shen, C. Li, J. Geng, X. Zhang, J. Gawith, J. Ma, Y. Liu, F. Grilli, and T. Coombs, "Power dissipation in HTS coated conductor coils under the simultaneous action of AC and DC currents and fields," Supercond. Sci. Technol., vol. 31, no. 7, 2018. 